\title{
Calcium Uptake and Protein Phosphorylation in Myenteric Neurons, Like the Release of Vasoactive Intestinal Polypeptide and Acetylcholine, Are Frequency Dependent
}

\author{
Denes V. Agoston and *Julianna Lisziewicz \\ Abteilung Neurochemie, Max-Planck-Institut für biophysikalische Chemie and *Abteilung Chemie, \\ Max-Planck-Institut für experimentelle Medizin, Göttingen, F.R.G.
}

\begin{abstract}
The mechanism of the electrical-to-chemical decoding involved in the preferential release of the transmitters acetylcholine and vasoactive intestinal polypeptide (VIP) by electrical field stimulation at low $(5 \mathrm{~Hz})$ and high $(50 \mathrm{~Hz})$ frequencies was studied in superfused myenteric neurons. The stimulation-induced uptake of ${ }^{45} \mathrm{Ca}^{2+}$ accompanying high frequency stimulation was markedly reduced by $10 \mu M$ nifedipine, a specific blocker of L-type voltagesensitive $\mathrm{Ca}^{2+}$ channels (VSCCs), as was also the preferential highfrequency release of VIP. By contrast, the ${ }^{45} \mathrm{Ca}^{2+}$ uptake during lowfrequency stimulation was somewhat lower per pulse, and neither this uptake nor the preferential release of acetylcholine occurring at this frequency was significantly reduced by nifedipine. These findings suggest that the release of acetylcholine and VIP involve different VSCCs. The pattern of in vitro protein thiophosphorylation in tissue extracts of differentially stimulated myenteric neurons involved polypeptides of $205,173,86,73,57,54,46,32,28$, and $24 \mathrm{kDa}$ and was also markedly stimulus and nifedipine dependent. This suggests that different phosphoproteins are involved during the frequencydependent activation of the different $\mathrm{Ca}^{2+}$ channels and exocytotic mechanisms. Key Words: Myenteric neurons-Differential frequency-dependent activation- $\mathrm{Ca}^{2+}$ channels-Transmitter releaseExocytosis-Protein phosphorylation. Agoston D. V. and Lisziewicz J. Calcium uptake and protein phosphorylation in myenteric neurons, like the release of vasoactive intestinal polypeptide and acetylcholine, are frequency dependent. $J$. Neurochem. 52, 1637-1640 (1989).
\end{abstract}

The myenteric plexus-longitudinal muscle preparation (MPLM) of the guinea pig ileum (Paton and Zar, 1968) is one of the richest mammalian sources of cholinergic neurons, and it also contains considerable amounts of pharmacologically active peptides, among them vasoactive intestinal polypeptide (VIP), substance $P$, and somatostatin (Costa et al., 1986), located in distinct storage granules, all of which can be separated by high resolution density-gradient centrif- ugation in a zonal rotor (Dowe et al., 1980; Agoston et al., 1985). We have made use of this preparaiton to compare the intracellular dynamics of acetylcholine ( $\mathrm{ACh}$ ) and the storage and release of VIP (Agoston et al., 1985a, 1988), because the latter transmitter is often detected in cholinergic nerve terminals and can be regarded as a cholinergic cotransmitter (reviewed by Agoston, 1988). In brief, VIP release is markedly dependent on the supply of newly synthesized storage granules by axonal transport, whereas ACh-rich synaptic vesicles can be recycled in the terminal, and $\mathrm{ACh}$ release is independent of axonal transport, within the time scale of these experiments.

In a study (Agoston et al., 1988) of the frequency dependence of the stimulus-evoked release of $\mathrm{ACh}$ and VIP from MPLM it was found that such release was markedly frequency dependent, ACh being preferentially released at low frequencies (LF, 2-5 Hz) and VIP at high frequencies (HF, 20-50 $\mathrm{Hz}$ ). The release induced by $\mathrm{K}^{+}$depolarization resembled that obtained at $8-10 \mathrm{~Hz}$, a frequency that does not favor release of either of the transmitters.

In considering the possible basis for this inversely related frequency dependence of release it was thought that the exocytosis of the ACh-rich synaptic vesicles and VIP-rich densecored vesicles present in these neurons (Agoston et al., 1985b) might occur at different sites, involve different $\mathrm{Ca}^{2+}$ channels, and utilize different exocytotic mechanisms. We have, accordingly, studied the uptake of ${ }^{45} \mathrm{Ca}^{2+}$ and the pattern of protein thiophosphorylation in MPLM strips as a function of frequency. The analysis was facilitated by the use of a dihydropyridine derivative nifedipine, a selective blocker of one (the $\mathrm{L}$ type) of the two main types ( $\mathrm{N}$ and $\mathrm{L}$ ) of voltagesensitive $\mathrm{Ca}^{2+}$ channels (VSCCs) known (Miller, 1987). Al-
Received January 18, 1989; accepted January 24, 1989.

Address correspondence and reprint requests to Dr. D. V. Agoston at Laboratory of Cell Biology, NIMH, Bldg 36, Rm 3A17, Bethesda, MD 20892, U.S.A.

The current address of Dr. J. Lisziewicz is National Cancer Institute, NIH, Bldg 41, Rm B503, Bethesda, MD 20892, U.S.A.

This work is dedicated to Prof. F. Cramer on the occasion of his 65 th birthday.
Abbreviations used: ACh, acetylcholine; ATP $\gamma \mathrm{S}$, adenosine 5 '- $(\gamma-$ thio)triphosphate; cAMP, cyclic AMP; DTT, dithiothreitol; HF, high frequency; LDC, large, dense-cored; LF, low frequency; MPLM, myenteric plexus-longitudinal muscle preparation; PMSF, phenylmethylsulfonyl fluoride; SDS, sodium dodecyl sulfate; SEL, small recycling electrolucent; TES, $N$-tris(hydroxymethy!)methyl-2-aminoethane sulfonate; VIP, vasoactive intestinal polypeptide; VSCC, voltage-sensitive $\mathrm{Ca}^{2+}$ channel. 
though many other $\mathrm{Ca}^{2+}$-channel blockers are known and could have been tested in this preparation, we felt that our preliminary results were of sufficient interest to merit publication at this stage.

\section{MATERIALS AND METHODS}

\section{Tissue preparation, transmitter release, and $\mathrm{Ca}^{2+}$ uptake}

Strips derived from MPLM preparations and weighing 50$150 \mathrm{mg}$ were prepared from identical regions of the ileum of guinea pigs and subjected to supramaximal electrical field stimulation in a superfusion chamber, using square wave pulses in trains containing equal numbers of pulses at LF ( 5 $\mathrm{Hz})$ and $\mathrm{HF}(50 \mathrm{~Hz})$, or to depolarization by $60 \mathrm{mM} \mathrm{KCl}$, as previously described (Agoston et al., 1985a, 1988). In some experiments nifedipine (Sigma; Munich, F.R.G.) was added to the perfusion medium at a final concentration of $10 \mu \mathrm{M}$. $\mathrm{ACh}$ and VIP release were measured and expressed as previously described (Agoston et al., 1988). $\mathrm{Ca}^{2+}$ uptake was measured, as described by Agoston et al. (1983) and Agoston and Kuhnt (1986), by adding ${ }^{45} \mathrm{Ca}^{2+}$ (specific radioactivity, $3 \mathrm{Ci} \cdot \mathrm{mmol}^{-1}$ ) to the perfusion medium in tracer amounts.

\section{In vitro thiophosphorylation}

Phosphorylation studies were performed on extracts of resting (control) or stimulated tissue by measuring the transfer of radioactive thiophosphoryl groups from $\left[{ }^{35}\right.$ S $]$ adenosine 5 '$\left(\gamma\right.$-thio)triphosphate $\left.\left({ }^{35} \mathrm{~S}\right] \mathrm{ATP} \gamma \mathrm{S}\right)$. Stimulated strips were comminuted in an Ultraturrax blender in ice-cold $50 \mathrm{~m} M$ $N$-tris(hydroxymethyl)methyl-2-aminoethane sulfonate (TES) buffer, pH 7.4, containing $0.4 \mathrm{~m} M$ EDTA, $0.5 \mathrm{~m} M$ dithiothreitol (DTT), $0.01 \mathrm{mM}$ phenylmethylsulfonyl fluoride (PMSF), and $10 \mu \mathrm{g} \cdot \mathrm{m}^{-1}$ leupeptin. The resulting $10 \%$ tissue suspension then was centrifuged in an Eppendorf centrifuge at $4^{\circ} \mathrm{C}$ for $5 \mathrm{~min}$; following protein determination, in vitro thiophosphorylation was performed in the supernatant. The $25-\mu 1$ reaction mixture contained (final concentrations): 50 $\mathrm{m} M$ TES, pH 7.4; $2.5 \mathrm{~m} M \mathrm{MnCl}_{2} ; 0.4 \mathrm{~m} M$ EDTA; $10 \mu M$ $\left[{ }^{35} \mathrm{~S}\right] \mathrm{ATP} \gamma \mathrm{S}$ (specific activity, $0.2 \mu \mathrm{Ci} \cdot \mu M^{-1}$ ); and $15-30$ $\mu \mathrm{g} \cdot \mu \mathrm{l}^{-1}$ of protein. In some experiments parallel samples were incubated in the presence of $10 \mu M$ nifedipine, or of a stable thio analogue of cyclic AMP (cAMP-Sp), or of $1.2 \mathrm{~m} M$ calcium. After incubations at $37^{\circ} \mathrm{C}$, usually for $10 \mathrm{~min}$, the reaction was terminated by adding sodium dodecyl sulfate (SDS) sample buffer and boiling for $5 \mathrm{~min}$. The SDS-solubilized proteins were electrophoretically separated on a $12.5 \%$ SDS-polyacrylamide gel and Coomassie Blue-stained; after being destained, the gels were dried and autoradiographed for 2-4 days at room temperature, using Amersham Betamax $x$-ray film. The developed films were scanned in a Shimadzu densitometer, and the areas under the peaks were integrated. Basal incorporation into the various proteins was expressed as a percentage of the total radioactivity recovered, and incorporation after LF or HF stimulation was expressed as a percentage of the corresponding basal incorporations. Total trichloroacetic acid-precipitable ${ }^{35} S$ incorporation was determined from small samples.

\section{RESULTS}

The activation of VSCCs, like transmitter release, is frequency dependent

Differential frequency dependence and pharmacology of ${ }^{4} \mathrm{Ca}^{2+}$ uptake. When MPLM strips were superfused with
${ }^{45} \mathrm{Ca}^{2+}$-containing Krebs-Ringer and LF or HF electrical field stimulation was applied, the kinetics of ${ }^{45} \mathrm{Ca}^{2+}$ uptake were found to be to some extent frequency dependent. Thus, even though after $5 \mathrm{~min}$ of stimulation the uptake of ${ }^{45} \mathrm{Ca}^{2+}$ had reached a plateau that was independent of stimulation frequency, $\mathrm{HF}^{45} \mathrm{Ca}^{2+}$ uptake had almost reached the plateau by $1 \mathrm{~min}$ but LF uptake had not quite reached it after $5 \mathrm{~min}$ (not shown). Given that the number of pulses delivered per train was identical, this indicated a difference in the kinetics of ${ }^{45} \mathrm{Ca}^{2+}$ uptake by differentially stimulated myenteric neurons. These differences became much more pronounced when the uptake of ${ }^{45} \mathrm{Ca}^{2+}$ took place in the presence of $10 \mu M$ nifedipine, a selective blocker of L-type $\mathrm{Ca}^{2+}$ channels. Nifedipine reduced the stimulated ${ }^{45} \mathrm{Ca}^{2+}$ uptake at 5 min during LF stimulation by only $10 \%$, a barely significant value (Fig. 1 ; compare block 10 with block 9 ), but reduced it by as much as $60 \%$ during $\mathrm{HF}$ stimulation (Fig. 1 ; compare block 12 with block 11 ). The net uptake of ${ }^{45} \mathrm{Ca}^{2+}$ induced by $\mathrm{K}^{+}$-stimulation also was reduced in the presence of nifedipine but only by $\sim 30 \%$. The unstimulated control uptake was not affected by nifedipine (not shown). These results suggest that at least two different VSCCs exist in MPLM preparations, one of which, probably an N-type channel, is preferentially activated at LF and the other, a nifedipine-sensitive L-type channel, is preferentially activated at $\mathrm{HF}$.

Effect of L-channel blockade on transmitter release. Nifedipine resolved ${ }^{45} \mathrm{Ca}^{2+}$ uptake into two frequency-dependent processes, namely, uptake mediated by $\mathrm{N}$-type channels preferentially activated by LF stimulation and L-type channels preferentially activated by HF stimulation. This finding strongly suggested that VIP release should be associated with
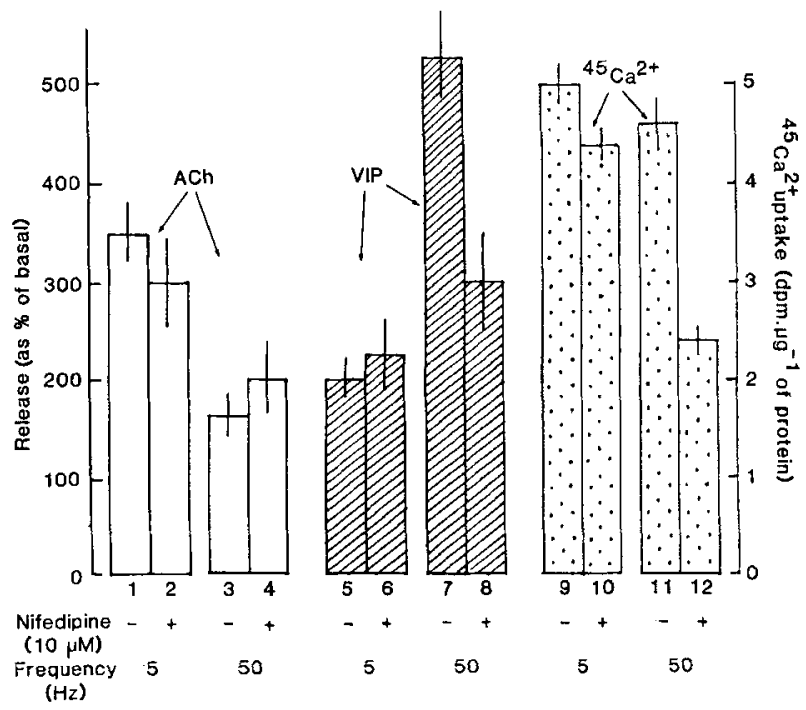

FIG. 1. The effect of the dihydropyridine derivative nifedipine, at a concentration of $10 \mu M$, on the release of $A C h$ (blocks 1-4) and ViP (blocks 5-8) and on the uptake of $\mathrm{Ca}^{2+}$ (blocks 9-12) by MPLM strips in response to $L F(5 \mathrm{~Hz})$ and $H F(50 \mathrm{~Hz})$ stimulation. The drug had little effect on any function at $5 \mathrm{~Hz}$ but at $50 \mathrm{~Hz}$ both VIP release and $\mathrm{Ca}^{2+}$ uptake were substantially depressed (compare block 8 with block 7 , and 12 with 11). Note that ACh release is lower at HF than at LF (compare blocks 3 and 1), whereas that of VIP is enhanced (compare block 7 with block 5 ). The basal, nonstimulated release $\left(\mathrm{g}^{-1}\right.$ of tissue $\left.\cdot \mathrm{min}^{-1}\right)$ of $\mathrm{ACh}$ was $106 \pm 15$ pmol $(n=18)$ and of VIP, $11 \pm 2 \mathrm{fmol}(n=18)$. The basal uptake of ${ }^{45} \mathrm{Ca}^{2+}$ was $1 \mathrm{dpm} \cdot \mu \mathrm{g}^{-1}$ of protein. 
the activation of L-type channels and $\mathrm{ACh}$ release by the activation of $\mathrm{N}$-type channels. This correlation was tested by studying the effect of nifedipine on ACh and VIP release. The results are also summarized in Fig. 1. Nifedipine was without effect on either the release of $\mathrm{ACh}$ (compare blocks 1 and 2) or the much lower release of VIP (compare blocks 5 and 6) induced by LF stimulation, but at $50 \mathrm{~Hz}$ it reduced the greatly augmented VIP release (compare block 7 with block 5) to close to the level found at LF (compare block 8 with blocks 7 and 5). By contrast, it had little or no effect on the reduced $\mathrm{ACh}$ output at $\mathrm{HF}$ (compare block 3 with blocks 4 and 1). In the case of stimulation with $60 \mathrm{mM} \mathrm{K} \mathrm{K}^{+}$(not shown), again there was little effect on $\mathrm{ACh}$ release but some effect on VIP release, the extent of which was consistent with equating the effect of high $\mathrm{K}^{+}$to stimulation at $8-10 \mathrm{~Hz}$.

\section{Variations in protein thiophosphorylation are induced in tissue extracts by differential stimulation in vivo}

Three major proteins of molecular masses 173, 86, and $54 \mathrm{kDa}$ and several minor proteins of molecular masses 205 , $73,57,46,32,28$ and $24 \mathrm{kDa}$ were thiophosphorylated in tissue extracts of nonstimulated MPLM strips (see Table 1, column 2). The total in vitro incorporation of $\left[{ }^{35}\right.$ S $]$ ATP $\gamma S$ in extracts of LF-stimulated MPLM strips was accompanied by an increase in several phosphorylated protein bands (Table 1 , column 3), especially the 205-, 57-, 54-, 46-, and 32-kDa bands, all of which showed a percentage increase greater than that of the total incorporation. By contrast, HF stimulation induced a lower total increase in incorporation (Table 1, column 4); however, the 205-, 73-, 54-, 46-, 32-, and 24-kDa proteins all showed a greater increase than that of the total incorporation. The $57-$ and $46-\mathrm{kDa}$ bands showed much less thiophosphate incorporation and the 73- and 24-kDa bands much more compared with that after LF stimulation (Table 1, column 5). Addition of the stable cAMP thio analogue or

TABLE 1. Effect of prestimulation on protein thiophosphorylation in strips of MPLM

\begin{tabular}{|c|c|c|c|c|}
\hline \multirow[b]{2}{*}{ Peak (kDa) } & \multirow{2}{*}{$\begin{array}{l}\text { Basal } \\
\text { (\% of } \\
\text { recovered } \\
\left.{ }^{35} \mathrm{~S}\right)\end{array}$} & \multicolumn{2}{|c|}{$\begin{array}{l}\text { Increase over } \\
\text { basal (as \% of } \\
\text { basal) }\end{array}$} & \multirow{2}{*}{$\begin{array}{c}\text { Ratio } \\
5 \mathrm{~Hz} / 50 \mathrm{~Hz}\end{array}$} \\
\hline & & $5 \mathrm{~Hz}$ & $50 \mathrm{~Hz}$ & \\
\hline $205^{a}$ & 3 & $813^{a}$ & 225 & $3.6^{a}$ \\
\hline 173 & 18 & 109 & 47 & 2.3 \\
\hline 86 & 40 & 97 & 42 & 2.3 \\
\hline $73^{b}$ & 2 & 140 & $220^{b}$ & $0.6^{b}$ \\
\hline $57^{a}$ & 4 & $\mathbf{2 8 5}^{a}$ & 69 & $4.1^{a}$ \\
\hline 54 & 15 & 320 & 136 & 2.3 \\
\hline $46^{a, c}$ & 6 & $369^{a}$ & $94^{c}$ & $3.9^{a, s}$ \\
\hline 32 & 1 & 300 & 300 & 1.0 \\
\hline 28 & 4 & 0 & -36 & - \\
\hline $24^{b}$ & 7 & 132 & $247^{b}$ & $0.5^{b}$ \\
\hline \multicolumn{2}{|c|}{ Total incorporation of ${ }^{35} \mathrm{~S}$} & 179 & 84 & 2.1 \\
\hline
\end{tabular}

Stimulation was at 5 or $50 \mathrm{~Hz}$ for $10 \mathrm{~min}$. Bold figures in columns 3 and 4 are percentage increases relatively greater than the total increase.

${ }^{a, b}$ Components whose thiophosphorylation is specifically increased by prestimulation at ${ }^{a} 5$ or ${ }^{b} 50 \mathrm{~Hz}$ relative to total.

${ }^{c}$ Raised when prestimulation at $50 \mathrm{~Hz}$ occurred in the presence of $10 \mu M$ nifedipine.
$\mathrm{Ca}^{2+}$ did not significantly change the phosphorylation patterns induced by different frequencies of stimulation. As expected from the transmitter-release and ${ }^{45} \mathrm{Ca}^{2+}$-uptake studies, elevated potassium induced a phosphorylation pattern that was intermediate between those after LF and HF stimulation (not shown).

Nifedipine acts selectively on the L-type of VSCC, so the effect of $10 \mu M$ nifedipine, during $50-\mathrm{Hz}$ stimulation, on the pattern of thiophosphorylation observed following such stimulation was investigated. The main selective change in the pattern was an inhibition of the thiophosphorylation of the 24-kDa protein, bringing the concentration of the thiophosphorylated product closer to that it had achieved after $5-\mathrm{Hz}$ stimulation. Because poststimulus thiophosphorylation probably represents a recovery process, this finding suggests that dephosphorylation of this protein may be involved in $\mathrm{N}$-type channel function.

\section{DISCUSSION}

Electrical signals reaching the nerve terminal via the axon open VSCCs, the L type of which is sensitive to dihydropyridine blockade but the $\mathrm{N}$ type is not (Miller, 1987). The resultant calcium influx triggers a sequence of events including phosphorylation of channel, vesicular, cytoskeletal, and receptor proteins followed by exocytosis and the release of transmitter (Reichardt and Kelly, 1983; Dunkley and Robinson, 1986; Armstrong and Eckert, 1987; Walker and Agoston, 1987; Augustine et al., 1987). The "classical" transmitter $\mathrm{ACh}$ is synthesized locally and stored in small recycling electrolucent (SEL) synaptic vesicles (reviewed by Whittaker, 1986). By contrast, peptide transmitters such as VIP are packaged, following perikaryal synthesis, into large, densecored (LDC) vesicles; these are then axonally transported in a fully loaded condition to the site of release (Nordmann, 1983). Differences in intracellular dynamics are also reflected in the finding that the classical transmitter is preferentially liberated at LF and the peptide at HF of electrical stimulation (Lundberg, 1981; Agoston et al., 1988). In the present work, we asked whether the differential frequency-dependent release of $\mathrm{ACh}$ and VIP from myenteric neurons can be correlated with a frequency-dependent activation of different VSCCs and if so, whether this is accompanied by different frequencydependent patterns of protein phosphorylation.

A clear correlation has emerged between the frequency dependence of the activation of the two main types $(L$ and $\mathrm{N}$ ) of VSCCs and that of the release of ACh and VIP. This finding permits the following conclusion: the exocytosis of the VIP-containing LDC-vesicles is triggered primarily by the influx of $\mathrm{Ca}$ through L-type $\mathrm{Ca}^{2+}$ channels opened by $\mathrm{HF}$ stimulation, whereas that of the cholinergic SEL vesicles depends on the opening of $\mathrm{N}$-type $\mathrm{Ca}^{2+}$ channels activated by LF stimulation. In neurons utilizing either ACh or VIP alone as transmitters, the two mechanisms can be visualized to exist in one tissue. However, for neurons utilizing both as cotransmitters, it would be necessary-as part of the functional consequences of transmitter coexistence (Bartfai et al., 1986) - to assume some form of topological separation of the two. Morphological studies have indeed indicated topological separation; the $N$-type channels appear to be concentrated at the active zones of the presynaptic membranes whereas the L-type are distributed on portions of the plasma membrane outside them (Miller, 1987). Also, exocytosis of LDC vesicles has been observed to occur peripherally to the active zones involved in the exocytosis of SEL vesicles ( $\mathrm{Zhu}$ 
et al., 1986). Other examples of a link between types of VSCC and the exocytosis of different types of storage particles are known; for example, the release of noradrenaline from sympathetic neurons and $\mathrm{ACh}$ from hippocampal slices both are dihydropyridine insensitive, whereas the release of substance $P$ from dorsal root ganglia is dihydropyridine sensitive (Miller, 1987; Pohorecki et al., 1987; Hirning et al., 1988).

The use of $\left[{ }^{35}\right.$ S]ATP $\gamma$ S for studying in vitro phosphorylation provides two advantages over the more frequently used [ $\gamma-{ }^{32}$ P]ATP: (1) the thio analogue is an effective specific substrate of kinases but not of ATPases (Yasuoka et al., 1982; Cassel et al., 1983); and (2) the rate of dephosphorylation of proteins that have been thiophosphorylated is much slower than that of the ${ }^{32} \mathrm{P}$-phosphorylated proteins (Cassel and Glaser, 1982). Taking advantage of thiophosphorylation results in the clear demonstration of frequency dependence in the pattern of stimulus-induced protein thiophosphorylation in the present work. Although the experimental design did not permit us to identify the phosphorylation of proteins according to their location (pre- or postsynaptic), it is tempting to relate these findings, together with the involvement of different VSCCs, to the different pathways of exocytosis activated by the application of two different frequencies.

Clearly, more work will be required to identify the role of the various protein kinase substrates and the significance of their poststimulus phosphorylation in transmitter release, but the fact that there are demonstrable frequency-dependent differences in the pattern of phosphorylation that can be modified by a $\mathrm{Ca}^{2+}$-channel blocker provides a useful starting point for such investigations.

Acknowledgment: We are grateful to Mr. G. H. C. Dowe for performing the $\mathrm{ACh}$ assays and to Herrn K. Seyfert of the Klinische Arbeitsgruppe für gastrointestinale Endokrinologie (Leiter, Dr. M. J. Conlon) for the VIP assays. We are also grateful to Prof. V. P. Whittaker for his interest and help in preparing the manuscript and to Prof. Dr. F. Eckstein for suggestions concerning the thiophosphorylation studies. The work was supported by the Deutsche Forschungsgemeinschaft (Wh 1/4-2) and the Max-Planck-Gesellschaft (Forschungsstipendium to J.L.).

\section{REFERENCES}

Agoston D. V. (1988) Cholinergic co-transmitters, in Handbook of Experimental Pharmacology, Vol 86 (Whittaker V.P., ed), pp 479-533. Springer Verlag, Heidelberg, F.R.G.

Agoston D. V. and Kuhnt U. (1986) Increased Ca-uptake of presynaptic terminals during long-term potentiation in hippocampal slices. Exp. Brain Res. 62, 663-668.

Agoston D., Hargittai P., and Nagy A. (1983) Effects of 4-aminopyridine in calcium movements and changes of membrane potential in pinched-off nerve terminals from rat cerebral cortex. J. Neurochem. 41, 745-751.

Agoston D. V., Kosh J. W., Lisziewicz J., and Whittaker V. P. (1985a) Separation of recycling and reserve synaptic vesicles from cholinergic nerve terminals of the myenteric plexus of guinea pig ileum. J. Neurochem. 44, 299-305.
Agoston D. V., Ballmann M., Conlon J. M., Dowe G. H. C., and Whittaker V. P. (1985b) Isolation of neuropeptide-containing vesicles from the guinea pig ileum. J. Neurochem. 45, 398-406.

Agoston D. V., Conlon J. M., and Whittaker V. P. (1988) Selective depletion of the acetylcholine and vasoactive intestinal polypeptide of the guinea-pig myenteric plexus by differential mobilization of distinct transmitter pools. Exp. Brain Res. 72, 535542.

Armstrong D. and Eckert R. (1987) Voltage-activated calcium channels that must be phosphorylated to respond to membrane depolarization. Proc. Natl. Acad. Sci. USA 84, 2518-2522.

Augustine G. J., Charlton M. P., and Smith S. J. (1987) Calcium action in synaptic transmitter release. Annu. Rev. Neurosci. 10, 633-693.

Bartfai T., Iverfeldt K., Brodin E., and Ogren S.-O. (1986) Functional consequences of coexistence of classical and peptide transmitters. Prog. Brain Res. 68, 321-331.

Cassel D. and Glaser L. (1982) Resistance to phosphatase of thiophosphorylated epidermal growth factor receptor in A431 membranes. Proc. Natl. Acad. Sci. USA 79, 2231-2235.

Cassel D., Pike L. J., Grant G. A., Krebs E. G., and Glaser L. (1983) Interaction of epidermal growth factor-dependent protein kinase with endogenous membrane proteins and soluble peptide substrate. J. Biol. Chem. 258, 2945-2950.

Costa M., Furness J. B., and Gibbins I. L. (1986) Chemical coding of enteric neurons. Prog. Brain Res. 68, 217-241.

Dowe G. H. C., Kilbinger H., and Whittaker V. P. (1980) Isolation of cholinergic synaptic vesicles from the myenteric plexus of guinea-pig small intestine. J. Neurochem. 35, 993-1003.

Dunkley P. R. and Robinson P. J. (1986) Depolarisation-dependent protein phosphorylation in synaptosomes: mechanisms and significance. Prog. Brain Res. 69, 273-293.

Hirning L. D., Fox A. P., McCleskey E. W., Olivera B. M., Thayer S. A., Miller R. J., and Tsien R. W. (1988) Dominant role of $\mathrm{N}$-type $\mathrm{Ca}^{2+}$ channels in evoked release of norepinephrine from sympathetic neurons. Science $239,57-61$.

Lundberg J. M. (1981) Evidence for coexistence of vasoactive intestinal polypeptide (VIP) and acetylcholine in neurons of cat exocrine glands. Morphological, biochemical and functional studies. Acta Physiol. Scand. (Suppl.) 496, 1-57.

Miller, R. J. (1987) Multiple calcium channels and neuronal function. Science 235, 46-52.

Nordmann J. J. (1983) Stimulus-secretion coupling. Prog. Brain Res. 60, 281-303.

Paton W. D. M. and Zar M. A. (1968) The origin of acetylcholine released from guinea-pig intestine and longitudinal muscle strips. J. Physiol. (Lond.) 194, 13-33.

Pohorecki R., French J., and Domino E. F. (1987) Extracellular calcium alters frequency modulation of $\left[{ }^{3} \mathrm{H}\right]$ acetylcholine release from hippocampal slices. Brain Res. 420, 199-203.

Reichardt L. F. and Kelly R. B. (1983) A molecular description of nerve terminal function. Annu. Rev. Biochem. 52, 871-926.

Walker J. H. and Agoston D. V. (1987) The synaptic vesicle and the cytoskeleton. Biochem. J. 247, 249-258.

Whittaker V. P. (1986) Acetylcholine storage and release. Trends Pharmacol. Sci. 7, 312-315.

Yasuoka K., Kawakita M., and Kaziro Y. (1982) Interaction of adenosine-5'-O-(3-thiotriphosphate) with $\mathrm{Ca}^{2+}, \mathrm{Mg}^{2+}$-adenosine triphosphatase of sarcoplasmic reticulum. J. Biochem. 91, 16291637.

Zhu P. C., Thureson-Klein $\AA$, and Klein R. L. (1986) Exocytosis from large dense cored vesicles outside the active synaptic zones of terminals within the trigeminal subnucleus caudalis: a possible mechanism for neuropeptide release. Neuroscience 19, 43-54. 